\title{
ZÉ-POVINHO E CIVILIZADOS: O DISCURSO HUMORÍSTICO NA IMPRENSA DA CIDADE DE NATAL NA BELLE ÉPOQUE
}

\section{ZÉ-POVINHO AND CIVILIZED: HUMOROUS DISCOURS IN THE PRESS OF THE CITY OF NATAL IN THE BELLE ÉPOQUE}

\author{
As palauras podem ter a leveza do vento e a força das tempestades \\ Vitor Hugo \\ Cellina Rodrigues Muniz ${ }^{1}$ \\ Universidade Federal do Rio Grande do Norte
}

\section{RESUMO}

A cidade de Natal, capital do estado nordestino do Rio Grande do Norte, viveu, na transição dos séculos XIX e XX, intensas transformações culturais, sociais e urbanísticas. Com os governos ligados ao grupo político dos Albuquerque Maranhão, chefiados pelo líder Pedro Velho, a capital potiguar vivenciou não só uma série de transformações na feição da cidade (criação de parques e praças, instalação de luz elétrica, bondes e telégrafos, inauguração de teatros, cinemas e cafés etc.) como passou por um processo civilizador (ELIAS, 1992) orquestrado pela elite letrada sobretudo por meio da imprensa, à maneira de outros centros urbanos do país. Inclusive por meio da imprensa tida como humorística. O propósito deste artigo - recorte de uma pesquisa de pós-doutorado - é ilustrar como jornais e colunas de humor da imprensa natalense daquele período (de 1880 a 1930, período que se convenciona designar Belle Époque) constituíram um campo discursivo (MAINGUENEAU, 2006; 2010; 2015) cujos posicionamentos revelam uma figuração estabelecidos X outsiders (ELIAS, 2000) que se manifestava não necessariamente por filiações político-partidárias (situação versus oposição), mas pelo caráter das fofocas (elogiosas ou depreciativas) que fomentavam tal imprensa humorística.

PALAVRAS-CHAVE: Discurso; Posicionamento; Imprensa; Humor; Natal; Belle Époque.

\section{ABSTRACT}

Natal, capital city of Rio Grande do Norte state, passed by intense cultural, social and urbanistic transformations, during the transition of XIX and XX centuries. Under the government connected to the political group of Albuquerque Maranhão, the 'potiguar' city has lived a series of transformations in the features of the city (parks and squares creation, electrical light installation, trams and telegraphs, theatres, movie theatres and cafés inauguration, etc.) and also, went through a civilizing process (ELIAS, 1992), orchestrated by the literate elite, mainly by means of the press, as the same manner of other urban centers in the country. Including the press considered humorous. The purpose of this communication - part of a postdoctoral research - is to illustrate how newspapers and columns of humor of the 'natalense' press from that period of time (from 1880 to 1930, period that is designated as Belle Époque) constituted a discursive field (MAINGUENEAU, 2001; 2011; 2016) whose positions (idem) reveal a figuration

\footnotetext{
1 Professora do Departamento de Letras e do Programa de Pós-Graduação em Estudos da Linguagem da UFRN. Graduada em Letras, Mestre em Linguística e Doutora em Educação com Pós-Doutorado em Linguística.
} 
established x outsiders (ELIAS, 2000) which was manifested not necessarily by political party affiliations (situation versus opposition), but by gossips character (complimentary or derogatory), encouraged by such a humorous press.

KEYWORDS: Discourse; Positioning; Press; Humor; Natal; Belle Époque.

\section{INTRODUÇÃO}

Não constitui nenhuma novidade a proposição de que, por meio da escrita, e também do humor, se travam combates e guerras. O conceito de posicionamento discursivo, aliás, implica esse caráter bélico, já que supõe uma tomada de posição num campo discursivo que se demarca por embates entre sujeitos e comunidades discursivas (MAINGUENEAU, 2015). Essas tomadas de posição implicam relações de acordo e/ou confronto entre lugares de enunciação e estão necessariamente atrelado a rotinas e regularidades das comunidades discursivas. Como afirma Maingueneau (2006, p. 40), "tais posicionamentos são eles próprios inseparáveis de grupos que os elaboram e os fazem circular, gerindo-os".

No campo da imprensa da Natal Belle Époque nem todos assumiam os mesmos posicionamentos: figuras de centro ou periféricas, carnavalescas ou civilizadoras, os sujeitos das letras vivenciavam entre si embates que eram uma forma de, em alguma medida, se afirmarem e se legitimarem nesse campo discursivo.

Mostrarei neste artigo de que maneira alguns desses embates foram travados. Tomo como corpus de análise não só alguns jornais humorísticos produzidos no período, bem como colunas de humor publicadas nos principais jornais diários da terra: A Republica, órgão fundado pelo líder republicano Pedro Velho e considerado o periódico oficial, assim como os dois principais jornais de oposição ao governo oligárquico dos Albuquerque Maranhão: o Diario de Natal e a Gaseta do Commercio.

\section{As condições de enunciação da imprensa em natal na belle époque}

Como se sabe, qualquer exercício de análise segundo as teorias do discurso precisa considerar as condições de sua enunciação que, constitutivamente, integram os enunciados. À luz de Maingueneau (2015, p. 33), trata-se aqui de seguir um modelo de análise que se interessa pela "maneira pela qual, em uma sociedade determinada, a ordem social se constrói pela comunicação". Ou, conforme afirma o autor (MAINGUENEAU, 2010, p. 151):

\footnotetext{
Refletir sobre a emergência das obras é considerar o espaço que lhes dá sentido, o campo em que se constroem os posicionamentos: doutrinas, escolas, movimentos... Trata-se da construção de uma identidade enunciativa que é tanto "tomada de posição" como recorte de um território cujas fronteiras devem ser incessantemente redefinidas. Esses posicionamentos não são apenas doutrinas estéticas mais ou menos elaboradas; são indissociáveis das modalidades de sua existência social, do estatuto de seus atores, dos lugares e práticas que eles investem e que os investem.
}

Nesse sentido, a relação entre intelectuais, imprensa e a ordem política e social em Natal na Belle Époque é o cerne das condições de enunciação daqueles enunciados publicados em jornais e colunas de humor. É esse o foco desta seção. 
É, de certa forma, consenso entre os estudiosos afirmar que os governos que instauraram a República no Rio Grande do Norte e se sucederam no poder durante os primeiros trinta anos do século XX foram responsáveis pela modernização do Estado e da capital Natal.

Sem dúvida, uma série de mudanças estruturais e comportamentais passou a ser empreendida na capital potiguar nos primeiros anos, de onde surgiu uma "Nova Natal". Sob o comando político do grupo oligarca republicano liderado por Pedro Velho", principalmente nos dois governos de Alberto Maranhão, foram tomadas medidas de aformoseamento e higienização da cidade, tal como fizera o prefeito Pereira Passos no Rio de Janeiro: aterros e criação de praças e passeios, aumento da malha urbana com a criação de mais um bairro (Cidade Nova, de onde seriam originados os bairros de Tirol e Petrópolis), construção do teatro Carlos Gomes (posteriormente, Teatro Alberto Maranhão), instalação de bondes (primeiramente puxados por burros, depois movidos a eletricidade), fundação de agremiações literárias e de grupos esportivos, de cafés, bares e banheiros públicos. Tudo isso apontava para um novo modo de viver e habitar a cidade, traduzindo e fomentando um anseio reinante de civilidade (cf. GURGEL, 2009; MARINHO, 2011).

A elite letrada que aspirava por aqueles ares de civilidade importados da Europa e da França também foi responsável pela instauração e solidificação da imprensa. Ao que tudo indica, a dinâmica de sociabilidade dos intelectuais da época passava, primeiramente, por encontros informais nos chamados cantões da cidade. A propósito das reuniões desses grupos em momentos ociosos, registra Emerenciano (2007, p. 63):

\begin{abstract}
...na Rua da Palha, atual Vigário Bartolomeu, existia o Cantão da Potiguarânia, nome de um bilhar de Ezequiel Wanderley. Era o cantão mais descontraído da cidade, freqüentado na sua maioria por jovens, que trocavam idéias sobre arte, literatura, jornalismo, tudo, enfim, que no momento atraísse a atenção da cidade. Freqüentavam religiosamente este Cantão: Uldarico Cavalcante, Antônio Marinho, Gothardo Neto, Sebastião Fernandes, Ferreira Itajubá, Pedro Melo, Aurélio Pinheiro, Cícero Moura, Celestino e Segundo Wanderley, José Pinto, Francisco Palma, dentre outros.
\end{abstract}

Desses cantões, foram os sujeitos letrados fundar grêmios e associações literárias, realizar encontros e conferências, publicar suas revistas e jornais, tais como $A$ Tribuna ou Oásis ${ }^{3}$.

Mas que não se pense que essa imprensa fosse necessariamente harmônica e que todos decantassem em uníssono o novo modo de vida civilizada em terras potiguares.

Além dos inúmeros pequenos jornais que circulavam de maneira irregular, muitos desses de caráter humorístico, três jornais diários merecem destaque: de um lado, $A$

Republica, criado por Pedro Velho em 1889 e que passou a representar o Diário Oficial do Estado; de outro lado, os jornais de oposição Diario do Natal, comandado por Elias Souto a partir de 1893, e a Gazeta do Commercio, impresso nas oficinas de Augusto

\footnotetext{
2 Pedro Velho de Albuquerque Maranhão (1856-1907) nasceu em Natal e formou-se em Medicina, na Bahia. Foi aclamado líder com a proclamação da República, que no RN ocorreu "sem barulho e sem violência", tendo vencido diversas eleições para deputado e senador. Seu grupo se manteve no poder até os anos de 1920, com o último mandato de Ferreira Chaves.

3 Para detalhes sobre os bastidores daquela imprensa, ver o livro de Pedro Pessoa de Mello, "Natal de ontem" (MELLO, 2006).
} 
Leite e gerenciado por Pedro Avelino a partir de 1901 (cf. FERNANDES, 1998; MELO, 1987).

Assim, a imprensa local não era lisa e homogênea. Isso se evidencia, sobretudo, em relação às práticas e medidas ligadas ao governo. Assim, por exemplo, embora muito se diga que Alberto Maranhão, sobretudo em seu segundo governo (1908-1914), tenha sido o "mecenas das letras" no período, nem todos os intelectuais da província lançavam loas ao representante da oligarquia dos Albuquerque Maranhão.

No jornal Diario de Natal, de 05/05/1904, por exemplo, foi publicada a notícia de ruptura do jornal Gaseta do Commercio, de Pedro Avelino, com o governo. Pedro Avelino, aliás, foi antes colaborador do jornal $A$ Republica, o jornal oficial da época e ligado ao governo. E seu jornal, junto com o Diario, foi empastelado em seguida, no ano de 1905, acontecimento que ilustra como as obras não se desvinculam de seu contexto bio/gráfico (MAINGUENEAU, 2001, p. 46).

Outro acontecimento que ilustra essa "guerra" foi a vinda a Natal do jornalista Sebastião Sampaio, do jornal carioca Gazeta de Notícias, a fim de ministrar uma conferência literária. Por elogiar o governo de Alberto Maranhão, particularmente em função da lei de incentivo aos autores locais, o jornalista recebeu a seguinte crítica por parte do Diario do Natal, em 17 de setembro de 1908:

\begin{abstract}
Quanto á famigerada lei de proteção á literatura, o colega não terá a ingenuidade, ou melhor infantilidade, de crer, de alma e coração, que ella tenha o necessário cumprimento. O tempo das ingenuidades passou; o mais é palanfrorio para armar ao efeito lá fora. Tem sido, é verdade, publicada u'a meia dúzia de livros a expensas do Estado; porem, si tal fosse tentatdo por um adversário da politica dominante, pensará o colega que seria satisfeito? Não pensará, garantimol-o. Que ella é um meio de proteção a alguns literatos da terra, longe de nós contestarmol-o, mas, entenda-se, literatos bem afeiçoados ao circulo dos próceres estaduais.
\end{abstract}

Nesse fogo cruzado, estavam também os periódicos e colunas de viés humorístico. Também o humor era, para usar uma expressão bakhtiniana, uma "arena de lutas" no campo da imprensa de então, como se vê, por exemplo, nesse texto publicado na coluna "Colmeia", assinada por "Abelha Mestra" (Segundo Wanderley), no jornal oficial $A$ Republica. Nessa edição de dezembro de 1901, ridicularizam-se notícias do jornal de oposição Diario de Natal, no caso, o surgimento de um novo jornal:

Posso informar ao publico que è inteiramente falsa a noticia dada pelo Caboré (diario de natal) sobre o apparecimento n'esta cidade de um novo jornal. O Mez. não passa de um brinquedo de meninos... Falta de reportagem é o diabo!

Antes de prosseguir em direção a esses embates discursivos, convém uma descrição geral dessa imprensa humorística. O que faço a seguir no próximo tópico.

\title{
2. O discurso humorístico na imprensa em natal na belle époque
}

O desenvolvimento da imprensa passa, necessariamente, por jornais e colunas de humor. De caráter efêmero e não-profissional, a imprensa humorística daquele período funcionava como espaço de atuação daqueles sujeitos que nem sempre tinham outras oportunidades de publicação. O estudo sobre as práticas de escrita daqueles senhores das 
letras reafirma, assim, a importância de não se deter apenas nos grandes autores e nas grandes obras reconhecidos como cânone (DARNTON, 2010).

Nem sempre os periódicos humorísticos se assumiam literalmente como humorísticos assim. Muitas vezes, apenas o título e sua apresentação de abertura davam a dimensão de que se tratava de um jornal voltado sobretudo para o humor. Foi o caso, por exemplo, do periódico $A$ Urucubaca, de 1915, que assim se apresentava: órgão defensor de seus próprios interesses ${ }^{4}$. O mesmo jornal ainda traz na sua primeira edição, de 3 de outubro de 1915, a seguinte epígrafe: Se o mal não existisse, era preciso inventá-lo.

Acontecia também de muitos desses jornais serem criados com nomes similares, referenciando-se uns aos outros, em curto espaço de tempo: O automóvel (1912) e $O$ Aeroplano (1915), O Prego (1914) e O Parafuso (1916), O Laço (1930) e O Cbicote (1931), para citar alguns. E ocorria ainda que muitos daqueles jornais em circulação não poderiam ser considerados como única e exclusivamente humorísticos, apresentando-se como meio sério, meio risão (cf. MELO, 1987).

Muitos elementos podem ser arrolados a respeito dos jornais e colunas de humor em Natal na Belle Époque. Basicamente, tratava-se de espaços em que os literatos podiam exercer uma autoria chistosa, contando anedotas e piadas em geral.

A piada, como textos de humor de modo geral (RASQUIN, 1985), se define basicamente por fazer confrontar dois esquemas de raciocínio distintos (normal x anormal, lógico x ilógico etc.), do que advém seu efeito de surpresa e riso diante de uma expectativa anulada. É o que ilustra esse exemplo, publicado no jornal $O$ Santelmo, na coluna humorística "Mozaico Alegre", de 26 de julho de 1891, fazendo apelo a um riso de zombaria (PROPP, 1992):

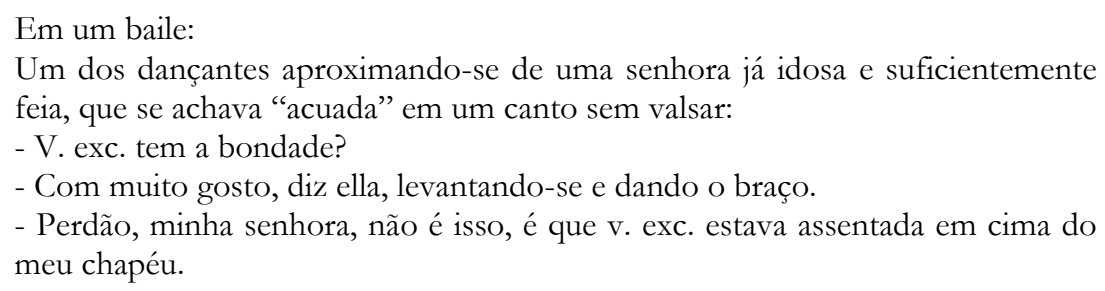

Mas o que quero enfatizar neste artigo é o fato de que, por meio dos jornais e colunas de humor, trocaram-se farpas e flechas, assim como também, em paralelo, eram feitas referências elogiosas. Comento, a seguir, algumas das colunas humorísticas dos diários da terra.

Três colunas de humor publicadas no jornal $A$ Republica na aurora do século XX merecem destaque: Colmeia, assinada por "Abelha Mestre"; Pensando e Rindo, assinada por "Tartarin"; e a coluna de "Lulú Capêta". Abelha Mestre e Lulú Capêta seriam pseudônimos, segundo Manoel Rodrigues de Melo (1987), de Segundo Wanderley e José Pinto, respectivamente. Já Tartarin, remete ao personagem fanfarrão do romance de Alphonse Daudet, de 1872, e cujo sujeito não consegui identificar.

A coluna Colmeia constituía-se de pequenas notas que abusavam, sobretudo, da zombaria de nomes ligados ao jornal Diario de Natal e episódios relacionados a tais pessoas.

${ }^{4}$ Ver também: MELO, 1987, p. 230. 
Como se sabe, o referido periódico comandado por Elias Souto ${ }^{5}$ fazia oposição ao governo oligarca e, consequentemente, ao jornal $A$ Republica. Pois a coluna assinada por Abelha Mestra (Segundo Wanderley), nos termos de Propp (1992), fazia apelo a um riso mau, que renega sarcasticamente seus adversários.

A zombaria em questão se volta particularmente para dois nomes: o primeiro, Gaspararito (ao que parece, Coronel Gaspar Monteiro) em função de um suposto episódio anedótico vivenciado por ele: este teria alegado que sua casa fora apedrejada por nomes ligados ao governo. Pelo que noticia a coluna do jornal adversário, Gaspar foi embora de Natal, nomeado para exercer cargo público em outro Estado. Ironicamente, assim escreve a Abelha Mestra:

\author{
Versos Tristes \\ Se me virem tristonha, pensativa, \\ Sem querer o meu mel fabricar... \\ Às pilherias, às troças meio esquiva: \\ - São saudades cruentas do Gaspar.
}

Pensando e Rindo era a coluna assinada pelo pseudônimo Tartarin. Dividia-se em três partes, condizentes com o propósito pressuposto no título: uma citação célebre que, por sua destacabilidade ${ }^{6}$, expressaria um pensamento a ser tomado como conduta; em seguida, um pequeno poema, geralmente de cárater romântico e não-assinado; e por último, uma piada.

Uma terceira coluna era escrita pelo próprio gerente e tipógrafo d'A Republica (José Mariano Pinto) sob o pseudônimo de Lulu Capeta, funcionava como uma mistura entre o fazer rir (divertir) e o fazer anunciar (divulgar/noticiar/vender). A mim parece que era a coluna que mais expressaria um posicionamento civilizador do humor naquele jornal: ainda que os exemplos observados na pesquisa pareçam visar a um riso bom (PROPP, 1992), a coluna, misturando tons de crônica e de poema, apresentava um caráter "ditatizante", como a querer influenciar o público em modos de se comportar.

Já nos dois outros principais jornais de Natal, ambos de oposição - Diario de Natal e Gaseta do Commercio - , destacam-se, respectivamente, as colunas: De Meu Canto, assinada por Nemo, e Rimando e Rindo, assinada ora por Zombeteiro, ora por Malazarte. A primeira coluna seguia o mesmo formato da coluna de Lulú Capêta: um ligeiro comentário noticioso seguido de uma quadra poética. Já a coluna Rimando e Rindo da Gaseta se assemelhava à coluna que evocava o mesmo título n'A Repubica, a seção Pensando e Rindo: primeiramente, uma citação - cuja destacabilidade conferia ao enunciado um tom de verdade incontestável -, depois um poema e finalmente uma piada ou anedota.

\footnotetext{
${ }^{5}$ Elias Souto (1848-1906), natural de Açu, é considerado o primeiro jornalista profissional do RN. Fundou vários jornais antes de criar O Nortista (1892), que em 1895 passaria a ser conhecido como Diario de Natal, principal jornal de oposição ao grupo político de Pedro Velho. No livro Personalidades Históricas, editado pela Fundação José Augusto e o Centro de Estudos e Pesquisas Juvenal Lamartine (1999), assim consta seu perfil: Elias Souto era paralitico desde jovem. Agressivo e inconformado com a situação politica de sua época, tornou-se adversário do então governador Pedro Velho (...)(que) o designara para ensinar em Pau dos Ferros, extremo oeste do Estado, apesar de suas extremas dificuldades de locomoção, duplamente agravando-se o problema por tratar-se da disciplina "Calistênica" (correspondente à Educação Física), mesmo sabendo que vivia numa cadeira de rodas.

6 Segundo Maingueneau (2014), essa condição caracteriza enunciados dados como autônomos, livres de qualquer amarra de natureza textual e enunciativa: podem ser fragmentos de textos originais que circulam em outros contextos e/ou enunciados imemoriais (provérbios, por exemplo) e cuja estrutura pregnante lhe confere um estatuto generalizante de verdade atemporal.
} 
Mas, para além das disputas políticas gerais, a leitura sumária desses jornais e colunas de humor permite pensar que esses embates discursivos se organizavam também em torno de uma figuração específica, atrelada sobretudo a modos de ser e estar na cidade de Natal naquele contexto específico, uma figuração discursiva que eu assim nomeio: civilizados versus zé-povinho.

\section{Entre civilizados e zé-povinho}

Mas, para além das disputas de ordem político-partidária, o campo discursivo da imprensa pareceu se organizar em função de outros critérios que aqui eu nomeio como civilizados x zé-povinho, ou seja: posicionamentos que elogiavam ou difamavam atitudes e comportamentos na nova ordem urbanística e social que se instaurava.

À maneira do estudo de Elias e Scotson sobre estabelecidos versus outsiders (2000), é preciso pensar esses embates entre sujeitos, grupos e posicionamentos como...

\section{...um equilíbrio instável de poder, com as tensões que lhe são inerentes(...) Um grupo só pode estigmatizar outro com eficácia quando está bem instalado em posições de poder das quais o grupo estigmatizado é excluído" (ELIAS E SCOTSON, 2000, p. 23).}

Pode-se dizer que, para além de pertencerem a grupos da situação ou oposição política, os embates discursivos também se manifestam no campo da imprensa natalense a partir de ajustamentos em relação a hábitos tidos como "educados", isto é, adequados à nova vida urbana segundo preceitos: civilizados versus zé-povinho. Tanto que o discurso civilizador se encontra em jornais de situação (A Republica) e de oposição (Diario de Natal, Gazeta do Commercio).

O critério diferenciador aí seria, pois, não só as filiações político-partidárias da época, mas também letrados/civilizados versus iletrados/zé-povinho. O imperativo maior me pareceu ser menos da ordem do "ler ou não" e do "publicar ou não", e sim de usos dos espaços e momentos públicos da cidade.

Assim, por meio dos impressos, fez-se a "guerra" entre "doutos" e "ignorantes".

Um exemplo que me parece bem emblemático dessa figuração discursiva está registrado no jornal $O$ Parafuso. Além de remeter à memória discursiva de terra dos papagerimú contra a qual se ressentia a concepção de civilidade da época, na edição de 5 de março de 1916, na coluna Damno-me..., uma notinha registrava: “...Contra uma senhora que foi a um enterro e trouxe um gerimú do cemitério!”

Percebe-se, por uma aparente hostilidade manifesta (dano-me, isto é, "me aborreço", "me vejo indignado com..."), a distinção entre juízos de valor sobre o que é nobre e o que é vil, a sugerir um riso que renega, pela zombaria, e que disciplina, pelo posicionamento civilizador.

Conforme esse exemplo, do jornal $A$ Rua, de 30 de janeiro de 1910, assinado pelo pseudônimo do poeta Gothardo Netto:

A Rua procurará sempre honrar a administração do illustre cavalheiro, levantando o véo que encobre certas chagas sociaes, convencida de que contribuirá com seu esforço e boa vontade para o saneamento moral de nossa 
prospera terra. Seremos intransigentes... E quem fôr pôdre que se quebre e quem não gostar coma menos.

Pantalhão Bodóque

Um elemento, portanto, que não pode deixar de ser abordado nessa figuração discursiva de "guerra" entre civilizados e zé-povinho é a fofoca. Segundo Elias e Scotson (2000, p. 121):

\begin{abstract}
A fofoca não é um fenômeno independente. O que é digno dele depende das normas e crenças coletivas e das relações comunitárias. (...) Estruturalmente, porém, a fofoca depreciativa (blame gossip) é inseparável da elogiosa (pride gossip), que costuma restringir-se ao próprio indivíduo ou aos grupos com que ele se identifica.
\end{abstract}

Com efeito, a tradição que relaciona fofoca e imprensa não se inicia no século XX: Darnton (2010), por exemplo, mostrou como os libelos clandestinos na França prérevolucionária já bebiam na maledicência e o quanto isso custou aos autores envolvidos.

O seguinte exemplo, publicado no jornal $O$ Telephono, registra a força que tinha a fofoca nessa dinâmica de embates entre posicionamentos e na própria configuração da cidade de Natal na Belle Époque:

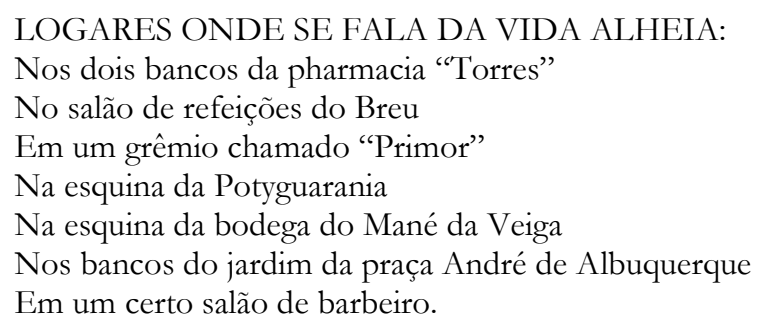

Conforme os posicionamentos e grupos dos quais os jornais e seus sujeitos participavam, as fofocas poderiam ser ora elogiosas, isto é, enaltecendo os sujeitos do próprio grupo, ora depreciativas ${ }^{7}$, ou seja, difamando os sujeitos do grupo contrário.

A coluna de Lulú Capêta, por exemplo, em edição d'A Republica de 1901, trata de tema que certamente era apreciado pelos intelectuais da época, independentemente de suas filiações políticas: o hábito de ir ao teatro. Fazendo uso de certa dose de autorrebaixamento, outro recurso típico de textos de humor, assim diz Lulu Capeta:

\title{
PALÁCIO \&LYRA
}

Diabos! Quando eu supunha ir fazer umas economias, para a festa de Natal, chega o sympatico actor Lyra com uma chusma de actores e etc. Eu lá estarei, deem as aguas por onde derem!...

O Lyra com sua grei

Chegou enfim a Natal

Proclamado como o Rei

Da Galhofa Theatral!

E com ele trouxe gente

Q'entre nós fará 'inferno'

Quando estrear brevemente Lá no Recreio Moderno!

\footnotetext{
${ }^{7}$ As fofocas depreciativas, aliás, têm uma longa tradição da imprensa, conforme mostrou Darnton (2010) com seu estudo sobre os escritos clandestinos na França do século XVII e XVIII, quando autores publicavam libelles cujas anedotas caluniavam figuras de importância na época.
} 
Lulú Capêta, como já dito, era José Luis Pinto, o gerente, tipógrafo e colunista do jornal $A$ Republica, de propriedade do grupo de Pedro Velho. Era considerado o jornal oficial do governo e, sendo assim, imprimia sempre um caráter elogioso às medidas ligadas à situação política e seus apoiadores. A construção do teatro e a realização em seu palco de diversos espetáculos eram, pois, algo a se enaltecer e o hábito de assistir a peças e outros espetáculos teatrais seria um hábito da civilidade que se pretendia instaurar. Do lado da oposição, entretanto, essas mesmas medidas podiam ser objeto de fofocas não elogiosas mas sim depreciativas.

É o que se registra, por exemplo, na nota que anuncia a inauguração do teatro Carlos Gomes (cujo nome mudou, em 1957, para Alberto maranhão) e a chegada de um gasômetro de acetileno, na edição intitulada "De meu canto", assinada pelo pseudônimo Nemo, no jornal Diario de Natal:

$$
\begin{aligned}
& \text { C'a por mim não sei se va } \\
& \text { A festa de inauguração } \\
& \text { (E commigo alguns doutores) } \\
& \text { Por medo da explosão. }
\end{aligned}
$$

O embate entre civilizados e zé-povinho, assumindo um tom disciplinador, ancorava-se também muito na contradição entre atitudes e comportamentos idealizados e aqueles observados na vida cotidiana, conforme apontou, inclusive, Saliba (2007). Os textos humorísticos se baseavam no choque entre dois esquemas básicos: a vida oficial e aparente versus a vida real e subterrânea, como registra a coluna "Coisas que nunca veremos", publicada no jornal O Parafuso, de 9 de dezembro de 1916:

\section{COISAS QUE NUNCA VEREMOS...}

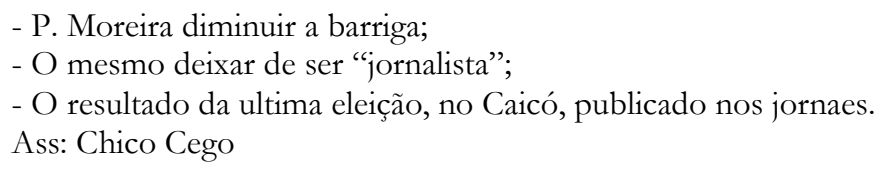

Ou ainda nesse exemplo, publicado na coluna "Musa do Povo", do jornal Diario de Natal, de 2 de junho de 1904:

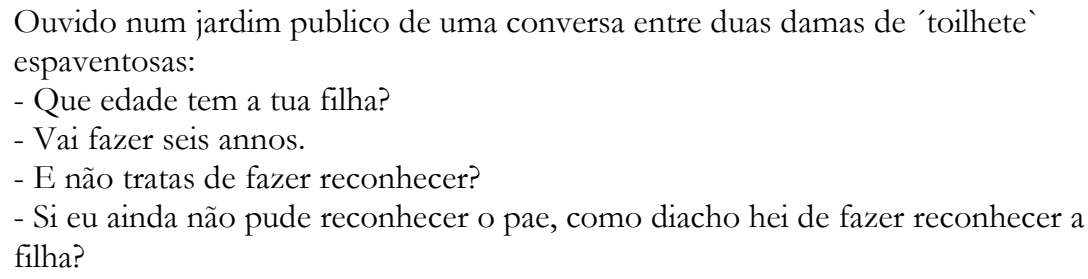

Assumindo, em certa medida, o mesmo posicionamento civilizador, o jornal de oposição Gaseta do Commercio, na edição de 17 de dezembro de 1907, publica uma nota de recriminação aos tipógrafos de Natal considerados como analfabetos e rodamontes, o que sugere novamente o tema da correção gramatical como ideal de pureza linguística e traço de pessoas civilizadas.

Outro exemplo que ilustra essa figuração seria o recado, ao que parece, encaminhado a Soarez (Sancho-Pansez), mais um sujeito das letras do período e possivelmente assinado com um pseudônimo assumido por Homem de Siqueira: 


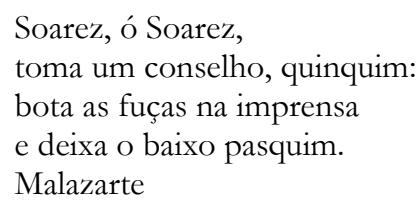

Ou ainda nesse outro caso, do jornal $A$ Rua, de 30 de janeiro de 1910, em que, na coluna de fofocas intitulada "Corre na rua... ", consta o seguinte comentário: “...Que isso de querer publicar porcarias e pasquinices, só se deixou para gente de duas caras."

Outro exemplo pode ser visto novamente na coluna "Colmeia", do jornal $A$ Republica. Nesse caso, fica bem explícita a relação de confronto entre grupos dos estabelecidos no poder e na imprensa oficial e aqueles que podiam ser considerados os outsiders, representados principalmente pelos jornais de oposição política Diario de Natal e Gąeta do Commercio. Colocados como alvo de um riso de zombaria por meio dessa fofoca depreciativa publicada em 9 de outubro de 1901, a pressupor uma condição de miséria para os oponentes e que deixa claro o conflito entre grupos a partir do seguinte diálogo, supostamente entre Pedro Thomáz e Augusto Leite:

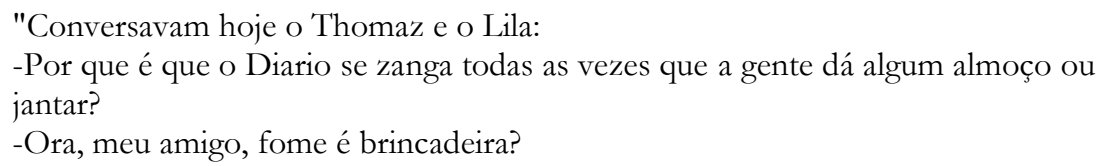

\section{CONSIDERAÇÕES FINAIS}

Neste artigo, tentei demonstrar como a imprensa de humor em Natal na Belle Époque assumiu um franco caráter de guerra por meio do apelo ao riso. Os embates entre posicionamentos discursivos não implicavam apenas as categorias "pró" versus "contra" o governo dos Albuquerque Maranhão ou jornais de situação versus jornais de oposição, mas ilustram, sobretudo, a figuração "civilizados" versus "zé-povinho".

Nessa figuração, as tomadas de posição também recaíam sobre as atitudes da própria imprensa. E embora a maioria assumisse as mesmas condutas - publicar anonimamente, tecer ofensas ou elogios, comentar a vida alheia e o cenário político local, nacional e exterior etc. - os duelos entre grupos tomavam como medida práticas típicas nas rotinas dos jornais.

Para encerrar e ilustrar com um último exemplo a guerra entre grupos e posições por meio dos jornais e colunas de humor em relação a essa tensão entre um humor mais popular e um humor mais erudito (cf. POSSENTI, 2010), tomo um trecho do texto de apresentação do jornal Zé-Povinho. Essa expressão se consagrou por meio do personagem de Bordalo Pinheiro na revista carioca Fon-Fon! (1907-1945) (cf. SILVA, 1990), mas sua origem parece ser da tradição oral. Tanto que, antes da referida revista, em Natal, em 1905, Pedro Thomaz editou um periódico humorístico homônimo, onde se pode ler:

Zé-Povinho é uma entidade real, vive em cada um de nós e no conjunto dos indivíduos das classes obscuras, que nem por isso deixam de ser dignas e de ter os mesmos direitos, às vezes mais sagrados, que as classes dirigentes. 


\section{REFERÊNCIAS BIBLIOGRÁFICAS}

DARNTON, Robert. O diabo na água benta. Ou a arte da calúnia e da difamação de Luís XIV a Napoleão. Tradução de Carlos Afonso Malferrari. São Paulo: Companhia das Letras, 2010.

ELIAS, Norbert e SCOTSON, John L. "Os estabelecidos e os outsiders": sociologia das relações de poder a partir de uma pequena comunidade. Tradução de Vera Ribeiro. Rio de Janeiro: Jorge Zahar Editores, 2000.

EMERENCIANO, João Gothardo Dantas (org.). Natal não há tal: Aspectos da História da Cidade do Natal. Natal: Secretaria de Meio Ambiente e Urbanismo/Departamento de Informação, Pesquisa e Estatística, 2007.

FUNDAÇÃO JOSÉ AUGUSTO/CENTRO DE ESTUDOS E PESQUISA JUVENAL LAMARTINE. Personalidades históricas do Rio Grande do Norte (séc. XVI a XIX). Natal: FJA, 1999.

GURGEL, Tarcísio. Belle Époque na esquina. O que se passou na República das Letras potiguar. Natal: Edição do autor, 2009.

MAINGUENEAU, Dominique. O contexto da obra literária. Tradução de Marina Appenzeller. São Paulo: Martins Fontes, 2001.

. Discurso e Análise do Discurso. Tradução de Sírio Possenti. Parábola editorial, 2015.

O discurso literário. Tradução de Adail Sobral. São Paulo: Contexto, 2010.

Frases sem texto. Tradução de Sírio Possenti et alli. São Paulo: Parábola, 2014.

MARINHO, Márcia. Natal também civiliza-se. Natal: EdUFRN, 2011.

MELO, Manuel Rodrigues de. Dicionário da Imprensa no Rio Grande do Norte (1909-1987). São Paulo: Cortez/Natal: Fundação José Augusto, 1987.

MELLO, Pedro de Alcântara Pessoa de. Natal de ontem: figuras e fatos de minha geração. 2 ed. Natal: Sebo Vermelho, 2006.

POSSENTI, Sírio. Humor, língua e discurso. São Paulo: Contexto, 2010.

PROPP, Vladimir. Comicidade e riso. Vários tradutores. São Paulo: Ática, 1992.

RASKIN, V. Semantic mechanisms of humor. Dordrecht: D. Riedel, 1985.

SALIBA, Elias Tomé. Raízes do Riso. A representação humorística na história brasileira: da Belle époque à Era do Rádio. São Paulo: Companhia das Letras, 2008.

SILVA, Marcos. República caricata: Zé Povo e o Brasil. São Paulo: Marco Zero, 1990.

Recebido em 06/03/2017

Aceito em 18/04/2017

Publicado em 19/04//2017 